\title{
DETERMINACIÓN DE SALMONELLA EN HUEVOS FRESCOS DE GALLINA (GALLUS GALLUS DOMESTICUS) QUE SE EXPENDEN EN LA CIUDAD DE GUAYAQUIL
}

\author{
AUTORES: Moreno Veloz Ema Nofret ${ }^{1}$ \\ Kuffó García Alfonso Cristóbal ${ }^{2}$
}

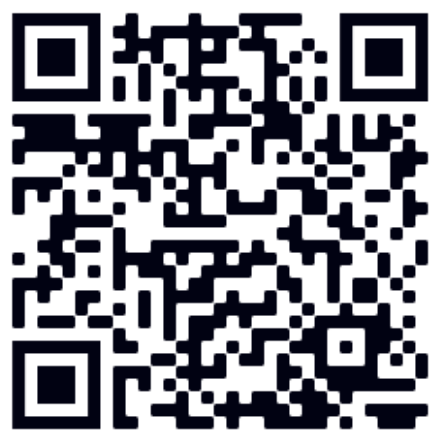

DIRECCIÓN PARA CORRESPONDENCIA:enofret@gmail.com

Fecha de recepción: 14/06/2019

Fecha de aceptación: 30/11/2019

\section{RESUMEN}

La Salmonella es una bacteria de crecimiento rápido que se encuentra en alimentos de origen animal como carne, leche y huevo, que al ser ingerida por el ser humano, estando en estado crudo, puede generar la enfermedad denominada Salmonelosis. Las manifestaciones de esta enfermedad son diversas y de importancia para la salud. El objetivo del presente estudio fue determinar la presencia de Salmonella en huevos frescos de gallina (Gallus gallus domesticus) que se expenden comercialmente en la ciudad de Guayaquil. Se elaboró un protocolo de análisis, utilizando métodos de recolección, aislamiento, identificación y tipificación de Salmonella spp. Se identificaron 16 puntos de muestreo entre mercados

privados y municipales en los cuatro puntos de la cuidad; se obtuvo un total de 980 cubetas de huevos. Se determinó un peso promedio de cada huevo de 61.4 gramos y tamaño promedio de 5.6 $\mathrm{cm}$. Un $34 \%$ presentó tierra, $26 \%$ heces fecales, $23 \%$ restos de plumaje de aves y $17 \%$ manchas de sangre. Se analizó tanto la parte externa como interna de los huevos, mediante la siembra en agua peptonada buferada e incubación a $37^{\circ} \mathrm{C}$ por $18-24 \pm 2 \mathrm{~h}$ para luego realizar las pruebas bioquímicas. De las muestras analizadas hubo ausencia de Salmonella en su totalidad. Se recomienda realizar estudios en otros puntos de la ciudad de Guayaquil, especialmente en centros de producción de huevos y durante la transportación de los mismos.

PALABRAS CLAVE: huevos, salmonella, bioquímica, mercados

DETERMINATION OF SALMONELLA IN FRESH CHICKEN EGGS (GALLUS GALLUS DOMESTICUS) THAT EXPANDS IN THE CITY OF GUAYAQUIL

\section{ABSTRACT}

\footnotetext{
${ }^{1}$ Química Farmacéutica, Magister en Ingeniería Ambiental, Docente, Universidad Católica de Santiago de Guayaquil, Guayaquil - Ecuador. Correo institucional: ema.moreno@cu.ucsg.edu.ec, electrónico: enofret@gmail.com

2 Ingeniero Agropecuario, Magister en Manejo Sostenible de Biorrecursos Acuáticos, Docente, Universidad Católica de Santiago de Guayaquil, Guayaquil - Ecuador. Correo institucional: alfonso.kuffo@cu.ucsg.edu.ec
} 
Moreno Veloz Ema Nofret, Kuffó García Alfonso Cristóbal, ...

Salmonella is a fast-growing bacterium found in animal foods such as meat, milk and eggs that when ingested by the human while in a raw state, it can generate the disease called Salmonellosis. The manifestations of this disease are diverse and of importance for health. The objective of this study was to determine the presence of Salmonella in fresh chicken eggs (Gallus gallus domesticus) that are commercially sold in the city of Guayaquil. An analysis protocol was developed, using methods of collection, isolation, identification and typing of Salmonella spp. 16 sampling points were identified between private and municipal markets in the four points of the city, with a total of 980 egg buckets obtained. Overall, eggs had an average weight of 61.4 grams and an average size of $5.6 \mathrm{~cm}$. A $34 \%$ had land, $26 \%$ feces, $23 \%$ bird plumage remains and $17 \%$ blood stains. Both the external and internal part of the eggs were analyzed, by sowing in buffered peptonated water and incubation at $37^{\circ} \mathrm{C}$ for $18-24 \pm 2 \mathrm{~h}$ and then performing the biochemical tests. Of the analyzed samples Salmonella was entirety absent. It is recommended to conduct studies in other parts of the city of Guayaquil, especially in egg production centers and during their transportation

KEYWORDS: eggs, Salmonella, Guayaquil, biochemistry, markets

\section{INTRODUCCIÓN}

Los alimentos de origen animal son con frecuencia, el medio de transmisión de la infección de un animal al hombre y siempre ha sido parte del campo de acción de la salud pública veterinaria asegurar que los alimentos sean aptos para el consumo humano. La Salmonelosis es una de las zoonosis transmitidas al hombre a través de los alimentos de origen animal como el huevo. Cuando un alimento está contaminado y existen en él ciertas propiedades para que se multiplique esta bacteria pueden causar enfermedad en aquel individuo que lo ingiera. El huevo como alimento de origen animal es básico en la nutrición de una población por su alto índice proteico y digestibilidad, por eso es importante conocer su calidad higiénica a la hora de adquirirlo para su consumo (Samartino y Eddi, 2019).

Los huevos de gallina recién puestos no suelen estar contaminados, sin embargo, algunos microorganismos pueden ganar acceso a éstos a través del oviducto. Los microorganismos presentes en el interior del huevo proceden principalmente del tracto intestinal de las aves, ponedero, polvo, cajas de embalaje y almacenamiento, entre otros y pueden penetrar a través de los poros del cascarón si éste se encuentra caliente y se contamina con materia fecal fría, entonces los gérmenes pasan al interior, conforme se va enfriando (Castillo, 1995).

Por todo lo antes expuesto y por ser la salmonelosis una de las causas de infección alimentaria, se realizó la investigación para conocer el grado de contaminación por Salmonella del huevo de gallina comercial.

Objetivos específicos

Detectar la presencia de Salmonella en la parte interna y externa de los huevos de gallina comercial que se expenden en la ciudad de Guayaquil para cuantificarla.

Tipificar especies de Salmonella presente en los huevos de gallina comercial que se expenden en la ciudad de Guayaquil para elaborar una tabla estadística comparativa.

Determinar las zonas con mayor presencia de Salmonella en los huevos de gallina comercial que se expenden en la ciudad de Guayaquil para elaborar el mapa de zonificación. 


\section{DESARROLLO}

Salmonella en huevos

Salmonella se transmite principalmente por el consumo de productos avícolas contaminados debido a la interacción con el sistema reproductivo de la gallina o por contaminación cruzada a través de manipuladores de alimentos o utensilios de cocina (Rincón, Ramírez y Vargas, 2011). Leyva et al (1996), realizaron la determinación de Salmonella y Enterobacterias totales a 330 muestras de huevos de gallina de producción nacional, en la cáscara y en el interior del huevo. En las primeras 180 muestras analizaron las yemas junto con la claras y en las 150 muestras restantes efectuaron el estudio por separado. Se aisló Salmonella en dos $(0,60 \%)$ y Enterobacterias en 58 $(17,57 \%)$ muestras de cáscara. No se aisló Salmonella en las muestras del interior del huevo. Se obtuvo crecimiento de Enterobacterias en una (0,3\%) muestra de clara y yema juntas, en $13(8,6$ $\%$ ) de las yemas y en ninguna de las claras. La calidad sanitaria de los huevos analizados fue satisfactoria tanto por la determinación de Enterobacterias totales como para el aislamiento de Salmonella.

En el estudio de Estrada y Valencia (2012), cuyo objetivo fue determinar la presencia de Salmonella spp. en huevos frescos de gallina en los principales mercados de la ciudad de Quito, recolectaron 282 huevos agrupados en 94 muestras (cada muestra constituida por tres huevos). Realizaron 2 recolecciones (de 47 muestras cada una), con un lapso de 30 días entre el inicial y el de replicación. Al cultivo bacteriológico, las colonias sugestivas de Salmonella, las analizaron mediante pruebas bioquímicas para su tipificación. En ninguna de las muestras se confirmó la presencia de Salmonella spp., pero se evidenciaron bacterias entéricas y ambientales que pudieran perjudicar la calidad del huevo e incluso producir problemas en la salud pública como: Pseudomona spp., Enterobacter cloacae, Pantoea spp., Provindencia rettgeri, Proteus mirabilis, Aeromona spp. y Burkhordelia cepacia.

Saenz, (2010) en el trabajo de tesis trabajó con un total de 15 de mercados municipales pertenecientes a 12 parroquias de la ciudad de Guayaquil para analizar el índice y grado de contaminación con Salmonella ssp, y tener un dimensionamiento real de este problema de Salud Pública como es la salmonelosis. Para ello se realizó un estudio investigativo con 300 huevos de gallina para consumo humano, provenientes de los mercados municipales y se recolectaron 20 muestras individuales de cada mercado en un lapso de 5 semanas (Noviembre-Dicimenbre 2009). Las muestras se sembraron en caldo de Tetrationato y se realizaron subcultivos a las 24 y 48 horas en agar SS (Salmonella-Shigella), de las colonias sospechosas de Salmonella, se realizó una identificación bioquímica para determinar con exactitud la existencia o no de la bacteria, obteniendo como resultado la presencia de Salmonella en $2 \%$ del total de las muestras. En la parroquia Sucre de la ciudad de Guayaquil, se encontró un $25 \%$, del total de las muestras de este sector.

Para demostrar la penetración de Salmonella typhimurium a través de la cáscara de los huevos recién incubados de pollos de engorde, éstos fueron rociados ligeramente con bacterias sobre el extremo romo del huevo o por contacto con basura contaminada de nidos secos. El tiempo de exposición para ambos grupos fue de 10 minutos; después, todos los huevos se desinfectaron e incubaron 19 días en condiciones normales. Las membranas corioalantoicas y los sacos vitelinos se cultivaron en caldo de infusión cerebro-corazón el día 19 para demostrar la penetración. El aislamiento de las bacterias de las membranas corioalantoicas en el grupo rociado fue del $100 \%$ y 
Moreno Veloz Ema Nofret, Kuffó García Alfonso Cristóbal, ...

en el grupo de contacto el $59 \%$; en cambio, en los sacos vitelinos del grupo rociado fue del $83 \%$ y del grupo de contacto $29 \%$. Estos resultados mostraron que aunque el agua mejoró la penetración de S. typhimurium, su presencia en la cáscara del huevo no es esencial para que ocurra la penetración (Padrón, 1990).

En otro estudio, se examinó la influencia del tiempo y la temperatura en la multiplicación de Salmonella enteritidis en huevos inyectados experimentalmente, teniendo como resultado un aumento en el número de $\mathrm{S}$. enteritidis con el aumento de la temperatura de almacenamiento de huevos. Hubo menos aumento de S. enteritidis en los huevos almacenados a $4{ }^{\circ} \mathrm{C}$ que en los huevos mantenidos a temperaturas superiores a $4{ }^{\circ} \mathrm{C}(\mathrm{P}<0.05)$. Se concluyó que las posibilidades de recuperación de $\mathrm{S}$. enteritidis se pueden aumentar 106 veces o más manteniendo los huevos a temperaturas de 21 ó $27^{\circ} \mathrm{C}$ durante más de 20 días y luego cultivar su contenido (Kim et al, 1989).

Soria (2012), en el estudio de la presencia de Salmonella spp. y las características físicas y pH del huevo para consumo humano, evaluó la sensibilidad de los aislamientos obtenidos frente a diferentes antimicrobianos de uso en medicina humana y veterinaria, las características físicas del huevo para consumo fueron evaluadas a través de las siguientes variables: peso y área total del huevo, observación macroscópica de la superficie; peso, porcentaje y espesor de la cáscara; color de la yema y pH del contenido de huevo.

Identificación utilizando el sistema BBL Crystal .

Las colonias presuntivas de Salmonella se identificaron mediante el sistema BBL Crystal (ID) de bacterias entéricas/no fermentadoras $(\mathrm{E} / \mathrm{NF})$ que contiene sustratos unidos a un cromógeno para detectar las enzimas que utilizan los microorganismos para metabolizar los distintos sustratos y al sufrir hidrólisis producen cambios de color que pueden ser detectados visualmente. El tiempo de incubación de los paneles $\mathrm{E} / \mathrm{NF}$ es de 18 - 20 h a $35-37$ oC. El número de perfil resultante se tabula en un PC con el Libro electrónico de códigos para los sistemas BBL Crystal ID y así obtener la respectiva identificación.

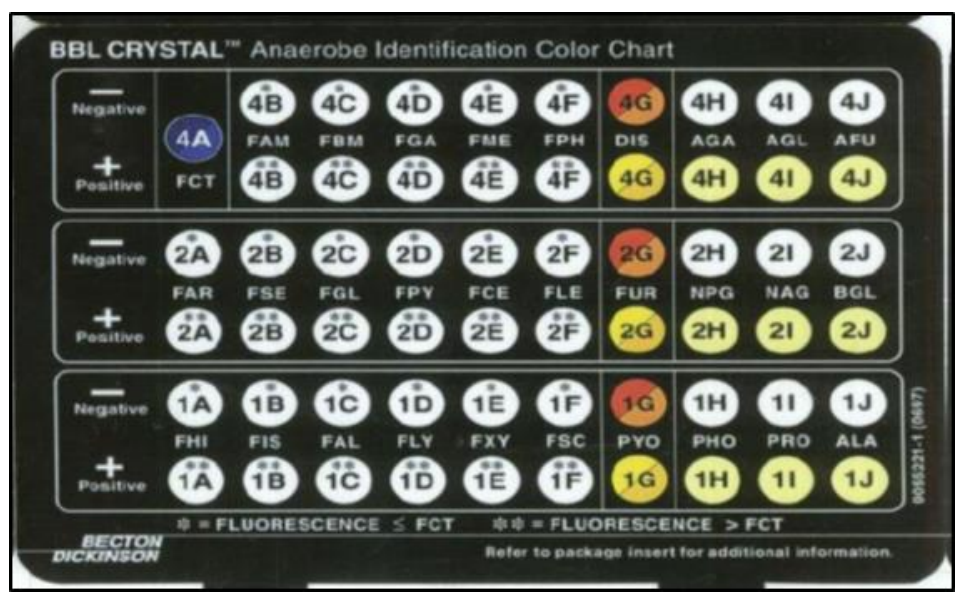

Figura 1. Perfiles para tabular los resultados del sistema BBL Crystal 


\section{ANÁLISIS DE RESULTADOS}

De las 980 muestras analizadas, en ninguna se identificó colonias típicas de Salmonella spp, lo que representó el $100.00 \%$ de ausencia. Este resultado también fue encontrado por (Estrada et al., 2012), en donde no obtuvieron presencia de Salmonella en las muestras analizadas. En otros estudios como el de (Leyva et al., 1996) encontraron Salmonella en la parte externa y no en la interna, es decir, no se aisló Salmonella en ninguna de las muestras del interior el huevo que está formado por la clara y yema.

Con relación a los huevos sucios, incluso con restos de heces fecales, éstos no presentaron índices de Salmonella, este resultado es casi similar al de (Soria, 2012) donde relaciona las características físicas y $\mathrm{pH}$ del huevo aplicando la metodología FDA/BAM (con modificaciones), donde obtuvo huevos con presencia de Salmonella spp., en el 1.8\% del total de las muestras. En este caso la suciedad en los huevos no condujo a la presencia de Salmonella ya que todas las muestras dieron resultado negativo.

Los resultados de esta investigación fueron obtenidos del análisis de los huevos de gallina comercializados en Guayaquil y realizada en el Laboratorio de Microbiología de la FTED - UCSG, en donde se estableció como variable la presencia / ausencia de Salmonella mediante las pruebas bioquímicas y la tipificación por BBL Crystal, para la identificación de Samonella.

\section{CONCLUSIONES}

En los huevos frescos de gallina muestreados en horas de la mañana y tarde, de los supermercados y mercados municipales de la zona norte, sur, este y oeste de la ciudad de Guayaquil, no se encontró Salmonella en la parte externa ni interna de los mismos.

En las pruebas bioquímicas no se obtuvo resultado positivo para Salmonella, debido a que no hubo crecimiento en ningunos de los medios de cultivo.

No se dio el aislamiento e identificación de los tipos de Salmonella en este estudio, a pesar que en algunas investigaciones han detectado presencia de algunos tipos de Salmonellas, sobre todo en aquellos huevos que han tenido suciedad en la superficie, pero no el interior, es decir, aunque exista presencia de algún tipo de Salmonella en la parte externa, ésta no pasa a contaminar el interior del huevo.

Al no determinar la presencia de Salmonella en los huevos, tanto en la parte externa como interna, no se pudo realizar la tipificación e identificación de especies de Salmonella por el método de BBL Crystal.

\section{REFERÉNCIAS BIBLIOGRÁFICAS}

Castillo, L.V. (1995). Determinación de Salmonella y enterobacterias totales en huevos frescos de gallina. Revista Cubana Aliment Nutr 1996; 10(2), http://bvs.sld.cu/revistas/ali/vol10_2_96/ali03296.htm.

Estrada, Juan P., \& Valencia, Byron A. (2012). Determinación de Salmonella spp. En huevos frescos de gallina en los principales mercados de la Ciudad de Quito. Recuperado de http://www.dspace.uce.edu.ec/handle/25000/599

Kim, Cj, Emery, Da, Rinke, H., Nagaraja, Kv, Y Halvorson, Da (1989). Efecto del tiempo y la temperatura sobre el crecimiento de Salmonella enteritidis en huevos inoculados experimentalmente. Enfermedades aviares, 735742. 
Leyva, V., Valdés, E., Cisneros, E. Y Pérez, O. (1996). Determinación de Salmonella y enterobacterias totales en huevos frescos de gallina. Instituto de Nutrición e Higiene de los Alimentos. Infanta No. 1158, municipio Centro Habana, Ciudad de La Habana, 10300, Cuba. Revista Cubans Aliment Nutr, 10 (2)

Padrón, Mario (1990). Penetración de Salmonella typhimurium a través de la cáscara de los huevos para incubar. Enfermedades aviares, 463-465.

Rincón, Diana P., Ramírez, Roman Y, \& VARGAS, Johana C. (2011). Transmisión de Salmonella enterica a través de huevos de gallina y su importancia en salud pública. Revista de la Universidad Industrial de Santander. Salud, 43(2).

Sáenz, Giancarlo. I. (2010). Determinación de Salmonella SPP, en huevos de gallina para consumo humano, recolectados en los mercados municipales de la ciudad de Guayaquil. Universidad Católica de Santiago de Guayaquil, Agropecuaria. Guayaquil: UCSG. Obtenido de http://repositorio.ucsg.edu.ec/handle/3317/974

Samartino, L. Y Eddi, C. (2019). Zoonosis de las áreas urbanas y periurbanas de América Latina. Revista Veterinaria Argentina. Vol. 36, No. 375.

soria, Mario A. (2012). Presencia de Salmonella y características físicas de huevos destinados a consumo humano (Doctoral dissertation). Argentina. Recuperado de: https://bibliotecavirtual.unl.edu.ar/ 